\title{
Physicochemical Aspects and Efficiency of Albuterol Nebulization: Comparison of Three Aerosol Types in an In Vitro Pediatric Model
}

\author{
Anne-Laure Sidler-Moix PhD, Ermindo R Di Paolo PhD, Ugo Dolci RPh, \\ Markoulina Berger-Gryllaki PhD, Jacques Cotting MD, and André Pannatier PhD
}

\begin{abstract}
BACKGROUND: Advances in nebulizer design have produced both ultrasonic nebulizers and devices based on a vibrating mesh (vibrating mesh nebulizers), which are expected to enhance the efficiency of aerosol drug therapy. The aim of this study was to compare 4 different nebulizers, of 3 different types, in an in vitro model using albuterol delivery and physical characteristics as benchmarks. METHODS: The following nebulizers were tested: Sidestream Disposable jet nebulizer, Multisonic Infra Control ultrasonic nebulizer, and the Aerogen Pro and Aerogen Solo vibrating mesh nebulizers. Aerosol duration, temperature, and drug solution osmolality were measured during nebulization. Albuterol delivery was measured by a high-performance liquid chromatography system with fluorometric detection. The droplet size distribution was analyzed with a laser granulometer. RESULTS: The ultrasonic nebulizer was the fastest device based on the duration of nebulization; the jet nebulizer was the slowest. Solution temperature decreased during nebulization when the jet nebulizer and vibrating mesh nebulizers were used, but it increased with the ultrasonic nebulizer. Osmolality was stable during nebulization with the vibrating mesh nebulizers, but increased with the jet nebulizer and ultrasonic nebulizer, indicating solvent evaporation. Albuterol delivery was 1.6 and 2.3 times higher with the ultrasonic nebulizer and vibrating mesh nebulizers devices, respectively, than with the jet nebulizer. Particle size was significantly higher with the ultrasonic nebulizer. CONCLUSIONS: The in vitro model was effective for comparing nebulizer types, demonstrating important differences between nebulizer types. The new devices, both the ultrasonic nebulizers and vibrating mesh nebulizers, delivered more aerosolized drug than traditional jet nebulizers. Key words: aerosol therapy; drug delivery; particle size distribution; jet nebulizer; vibrating mesh nebulizer; ultrasonic nebulizer. [Respir Care 2015;60(1):38-46. () 2015 Daedalus Enterprises]
\end{abstract}

\section{Introduction}

Aerosol therapy, particularly with bronchodilators, is a mainstay for patients with asthma, bronchospasm, or ob-

\footnotetext{
Drs Sidler-Moix, Di Paolo, Berger-Gryllaki, and Pannatier and Mr Dolci are affiliated with Department of Pharmacy, University Hospital, Lausanne; Dr Cotting is affiliated with the Pediatric Intensive Care Unit, University Hospital, Lausanne; Drs Sidler-Moix and Pannatier are affiliated with the School of Pharmaceutical Sciences, University of Geneva, University of Lausanne, Geneva, Switzerland.
}

The authors have disclosed no conflicts of interest.

This research was supported by the Department of Pharmacy and the Pediatric Intensive Care Unit, University Hospital, Lausanne, Switzerland. structive lung disease who require mechanical ventilation. ${ }^{1-11}$ Nebulized $\beta_{2}$ agonists are commonly prescribed for mechanically ventilated infants and children. ${ }^{1,3,5-7}$ Various inhalation systems are available to generate aerosol during mechanical ventilation, for example, nebulizers and metered-dose inhalers with or without a spacer device. Only 2 comparisons between these administration methods have been reported for ventilator-dependent infants or children 7,8 ; their conclusion was that a metered-dose in-

\footnotetext{
Correspondence: Anne-Laure Sidler-Moix PhD, Department of Pharmacy, Centre Hospitalier Universitaire Vaudois, Rue du Bugnon 46, 1011 Lausanne, Switzerland. E-mail: anne-laure.sidler-moix @ hopitalvs.ch.
}

DOI: $10.4187 /$ respcare. 02490 
haler is as efficacious as a nebulizer. Therefore, the choice between metered-dose inhaler and jet nebulizer is mostly motivated by the preference of the physician or the respiratory therapist. Even if the current literature is indecisive, ${ }^{2,4}$ jet nebulizer remains the most commonly used delivery system for mechanically ventilated patients. ${ }^{4}$

In order to optimize aerosol therapy in mechanically ventilated children, previous studies tested up to $6 \mathrm{com}-$ mon jet nebulizers under standard conditions. ${ }^{12,13}$ As changes in solute concentration and temperature during nebulization could have an effect on aerosol size, a previous study focused on the physicochemical aspects of nebulization, namely, changes in osmolality, drug concentration, temperature, $\mathrm{pH}$, and droplet size in albuterol aerosol preparations. ${ }^{13}$ Another study analyzed the influence of jet nebulizer brand and nebulization mode on albuterol delivery using an in vitro pediatric mechanical ventilation model simulating a $10-\mathrm{kg}$ child. ${ }^{12}$ These 2 studies highlighted some lack of constancy of jet nebulizers during nebulization and a marked variability between jet nebulizer brands.

A new generation of high-efficiency electronic nebulizers has been developed that overcomes some disadvantages of conventional nebulizers. An ultrasonic nebulizer device is equipped with an infrared control that enables the ultrasonic generation of aerosol, greatly diminishing residual solution and consequently drug waste and allowing $30 \%$ shorter inhalation times compared with traditional jet nebulizers. ${ }^{11}$ Ultrasonic nebulizers use the piezoelectric effect to convert high-frequency oscillations into mechanical vibrations that are transmitted to the solution to be nebulized or to an intermediate medium, mostly distilled water. The high-frequency vibration waves generate aerosol particles, which are either carried away from the nebulizer in an air stream or inhaled by the patient during inspiration. Another recently developed device, the Aerogen professional nebulizer system (Aerogen Pro), uses a vibrating mesh or plate with multiple apertures through which the medication solution is pushed by high-frequency vibrations produced by a battery-powered piezoelectric crystal to generate a fine-particle, low-velocity aerosol, using no propellants or compressors and adding no extra flow during nebulization. ${ }^{14,15}$ This device was quickly adopted in our hospital without any in-depth assessment of its technical characteristics. In our experience, its vibrating membrane is fragile and requires careful use, frequent cleaning with a disinfectant, and rinsing with $\mathrm{NaCl}$ isotonic solution or sterile water to avoid the obstruction of its apertures.

The aim of this study was to develop an in vitro model to test different nebulizer types and to compare the most efficient jet nebulizer tested in our previous study ${ }^{13}$ with these new types of devices, namely the ultrasonic nebulizer (Multisonic) and the vibrating mesh nebulizers (Aero-

\section{QUICK LOOK}

\section{Current knowledge}

Aerosol therapy can be delivered using a wide variety of nebulizers with different physical principles. In recent years, the use of ultrasonic and mesh nebulizers have been shown to enhance aerosol delivery compared with jet nebulizers.

\section{What this paper contributes to our knowledge}

Both ultrasonic and mesh nebulizers delivered more aerosol in this model compared with traditional jet nebulizers. The respirable fraction of aerosol was greatest with the mesh nebulizers.

gen Pro and its single-patient-use version Aerogen Solo). To this end, we monitored albuterol output and physical characteristics such as pulmonary deposition, particle size, temperature changes during nebulization, and osmolality in a $10-\mathrm{kg}$ body weight pediatric model.

\section{Methods}

\section{Nebulizers}

The following commercially available models of nebulizers were tested: jet nebulizer (Sidestream Disposable, Profile Therapeutics, Bognor Regis, United Kingdom; 5 units from the same batch), ultrasonic nebulizer (Multisonic InfraControl, Schill GmbH, Probstzella, Germany; 5 different medicine inlets with the same nebulizer), and vibrating mesh nebulizers $(n=5)$ (Aerogen Pro and Aerogen Solo, Aerogen, Dangan Galway, Ireland; 5 different units with the same control module) (Fig. 1). Aerogen Solo is a single-patient-use, multiple-dose vibrating mesh device using the same generator as Aerogen Pro. In 3 distinct experimental steps, the following parameters were tested in triplicate: (1) duration of nebulization, temperature variation, and albuterol deposition; (2) osmolality evolution and albuterol and electrolyte concentrations during nebulization; and (3) particle size distribution of each device to determine the respirable fraction.

\section{In Vitro Model}

The in vitro model comprised 3 parts: (1) the nebulizer; (2) the connectors: namely, a T-piece for the pediatric ventilator circuits (Aerogen Ltd. for jet nebulizer and vibrating mesh nebulizers, and a direct connector for ultrasonic nebulizer), which was connected to a Y-piece by an angled piece; for the jet nebulizer, the Y-piece blocked the 

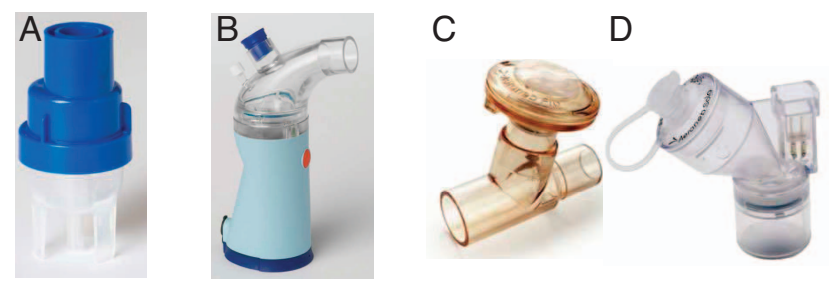

Fig. 1. Devices used in the study. A: Sidestream; B: Multisonic InfraControl; C: Aerogen Pro; D: Aerogen Solo. (Courtesy Aerogen.)

double Venturi; and (3) 4 filters: 2 superposed low-resistance absolute filters (Respirgard II 303, Vital Signs Ltd, Littlehampton, United Kingdom) connected on both branches of the thermostated $\left(37.5 \pm 0.5^{\circ} \mathrm{C}\right)$ Y-piece to simulate the lungs and to avoid filter saturation and loss of albuterol (Fig. 2). The propulsion of the nebulized solution was achieved with dry air $(10 \mathrm{~L} / \mathrm{min})$, chosen to mimic the mean inspiratory flow of a $10-\mathrm{kg}$ child. For the jet nebulizer, the air flow was $6 \mathrm{~L} / \mathrm{min}$ to produce the aerosol and $4 \mathrm{~L} / \mathrm{min}$ of additional air flow to propel it to the filters. For the ultrasonic nebulizer and the vibrating mesh nebulizers, the air flow was $10 \mathrm{~L} / \mathrm{min}$ to allow comparison. Stable flow was achieved with a mass flow meter (El-Mass Flow Meter F201C-FB-22-V, Bronkhorst High Tech BV, Ruurlo, The Netherlands). Our model does not simulate tidal breathing but rather delivery of aerosol under constant flow. The iso-osmotic nebulized solution consisted of $4 \mathrm{~mL}$ of $0.05 \%$ albuterol sulfate diluted in $0.9 \%$ sodium chloride ( $2 \mathrm{mg}$ of albuterol sulfate: Ventolin $0.05 \%$ unit dose, GlaxoSmithKline, Schönbühl, Switzerland).

\section{Duration, Aerosol Output, Albuterol Deposition, and Temperature}

Nebulization was stopped automatically (with the ultrasonic nebulizer), or when the reservoir was empty (with the vibrating mesh nebulizers). For the jet nebulizer, the duration of nebulization was set to $15 \mathrm{~min}$, which corresponds to the sputtering time observed with this brand. For each experiment, the nebulizers and different parts of the in vitro model were weighed with precision before and after nebulization. Albuterol remaining in the nebulizer and deposited on connectors and filters was extracted with purified water. The different solutions were frozen to $-18^{\circ} \mathrm{C}$. Previous tests ${ }^{16}$ had shown that $>98 \%$ of the drug was retained on the filter after 8 weeks of freezing. The technique to extract filters was validated with 10 filters loaded with known amounts of albuterol. Extraction recovery was $100.5 \pm 0.3 \%$. Albuterol concentrations were determined using a high-performance liquid chromatography system (Varian, Palo Alto, California) equipped with a ProStar 230 solvent delivery module, a ProStar 410 autosampler, and coupled with a fluorimetric detector

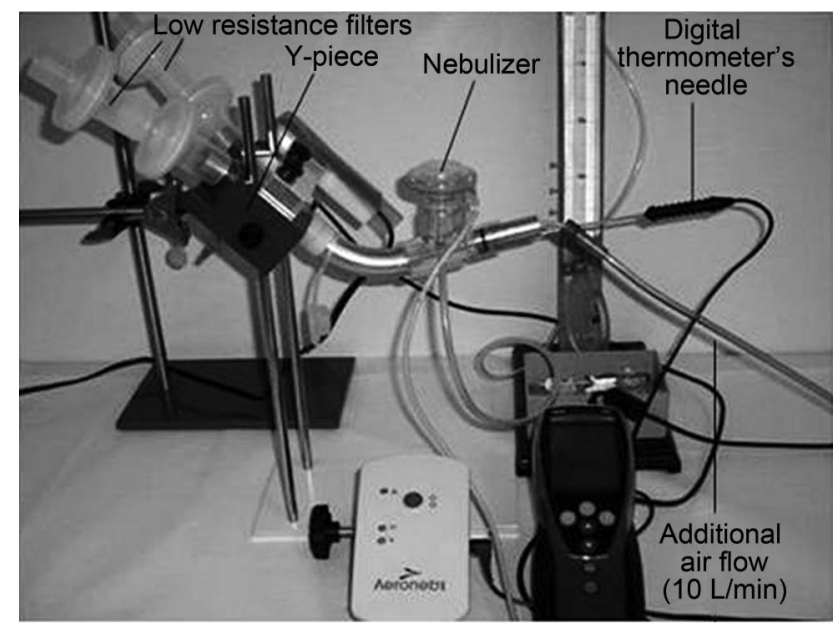

Fig. 2. In vitro model with Aerogen Pro: Y-piece with 2 low-resistance filters on each side.

(Jasco FP-920 intelligent fluorescence detector, Tokyo, Japan) operating at an excitation wavelength of $275 \mathrm{~nm}$ and an emission wavelength of $310 \mathrm{~nm}$. The column was a Chromolith Performance RP $18 \mathrm{e}(100 \times 4.6 \mathrm{~mm})$ equipped with a Chromolith Performance RP $18 \mathrm{e}$ $(10 \times 4.6 \mathrm{~mm})$ precolumn (Merck KgaA, Darmstadt, Germany). The following mobile phase was used: $20 \%$ acetic acid $1 \%$ in methanol and $80 \%$ acetic acid $1 \%$ in purified water. The flow was $2.0 \mathrm{~mL} / \mathrm{min}$, and the injection volume was $50 \mu \mathrm{L}$. The method was validated with a procedure adapted from the Société Française des Sciences et Techniques Pharmaceutiques (SFSTP) guidelines. Statistical data were analyzed with a software dedicated to the validation of physicochemical methods (e-noval, Arlenda, Liège, Belgium). The validation of the method gave a limit of detection of $1.2 \mathrm{ng} / \mathrm{mL}$, whereas the lower and upper limits of quantification were 22.2 and $200 \mathrm{ng} / \mathrm{mL}$, respectively. The precision (coefficient of variation) in inter- and intra-assays was $<4.2 \%$ at all concentration levels. The accuracy ranged from 99.8 to $100.4 \%$ of the mean values. The total quantity of albuterol initially introduced into every nebulizer was determined from the various weighings of the solution of nebulization, its practical concentration (determined by high-performance liquid chromatography), and its density. The average density was determined on 5 different plastic ampoules of Ventolin $0.05 \%$ by means of a densitometer (DMA48 density meter, Anton Paar, Austria).

The aerosol output $(\mathrm{g} / \mathrm{min})$ was calculated as the difference of the weighted chamber before and after nebulization divided by the time of nebulization. The albuterol dose (in $\mathrm{mg}$ ) emitted by the nebulizers was calculated as the nominal minus the residual quantity in the reservoir. The fractional parts of albuterol remaining in the reservoir, deposited in the connectors and filters (pulmonary frac- 


\section{Physicochemical Aspects and EfFiciency of Nebulization}

Table 1. Duration of Nebulization and Flow Rate of Aerosol in the In Vitro Model

\begin{tabular}{|c|c|c|c|c|}
\hline Nebulizers & $\begin{array}{l}\text { Duration of Nebulization* } \\
\qquad(\mathrm{min}) \dagger\end{array}$ & $\begin{array}{l}\text { Aerosol Output } \neq \\
\text { (g of solution/min) } \dagger\end{array}$ & $\begin{array}{l}\text { Albuterol Emitted Dose } \S \\
\qquad(\mathrm{mg}) \dagger\end{array}$ & $\begin{array}{l}\text { Albuterol Emitted Dose } \\
\qquad(\%)\end{array}$ \\
\hline Jet $(\mathrm{SN})$ & $15.0 \pm 0.0$ & $0.15 \pm 0.01$ & $0.87 \pm 0.08$ & $42.40 \pm 4.01$ \\
\hline Ultrasonic (MN) & $5.8 \pm 0.6$ & $0.52 \pm 0.05$ & $1.41 \pm 0.11$ & $68.20 \pm 5.06$ \\
\hline Vibrating mesh (AP) & $9.9 \pm 1.8$ & $0.40 \pm 0.08$ & $1.99 \pm 0.03$ & $96.40 \pm 1.20$ \\
\hline Vibrating mesh (AS) & $10.2 \pm 1.0$ & $0.39 \pm 0.04$ & $2.01 \pm 0.01$ & $97.85 \pm 0.55$ \\
\hline \multirow[t]{3}{*}{$P<.001$} & SN vs MN & SN vs MN & SN vs AP/AS & SN vs AP/AS \\
\hline & $\mathrm{SN}$ vs $\mathrm{AP} / \mathrm{AS}$ & SN vs AP/AS & MN vs AP/AS & MN vs AP/AS \\
\hline & MN vs AP/AS & MN vs AS & MN vs SN & MN vs SN \\
\hline$P<.05$ & & $\mathrm{MN}$ vs $\mathrm{AP}$ & & \\
\hline $\begin{array}{l}\text { The duration of nebulizatior } \\
\dagger \text { Mean } \pm \text { SD }(n=5) \text {. } \\
\text { ₹ Quantity of nebulized soluti } \\
\S \text { Quantity of albuterol nebuli } \\
\text { SN = Sidestream nebulizer } \\
\text { MN = Multisonic nebulizer } \\
\text { AP = Aerogen Pro nebulizer } \\
\text { AS = Aerogen Solo nebulizer }\end{array}$ & $\begin{array}{l}\min . \\
\text { (g/min) } \\
\text { (quantity of albuterol residual quant }\end{array}$ & uterol) & & \\
\hline
\end{tabular}

tion), were determined as a percent of the nominal dose. During nebulization, the temperature was measured both in the reservoir solution and in the center of the T-piece by using a fast digital thermometer (Testo 735-2, Testo AG, Mönchaltrof, Switzerland).

\section{Osmolality and Concentration of Albuterol Sulfate in the Reservoir Solution}

The osmolality of the solution in the reservoir was determined with a cryomatic osmometer (model 3D3; Advanced Instruments, Norwood, Massachusetts) calibrated with 100 and $1,500 \mathrm{mOsm} / \mathrm{kg}$ standards. Measurements were made after $0,1.5,3.0,4.5,6.0,7.5$, and $9.0 \mathrm{~min}$ of nebulization for vibrating mesh nebulizers, after 1 min during $6 \mathrm{~min}$ for the ultrasonic nebulizer, and after $0,1.5,3.0$, $4.5,6.0,7.5,10.0$, and $15.0 \mathrm{~min}$ for the jet nebulizer. A new solution was used at each time interval. The interval between measurements chosen for the ultrasonic nebulizers was shorter because of their shorter time of nebulization. Albuterol concentrations were defined as described above.

\section{Particle Size Distribution and Respirable Fraction}

The particle size distribution was measured by laser diffraction with a Mastersizer S granulometer (Malvern Instruments, Malvern, United Kingdom) equipped with a conventional 300-mm Fourier lens. ${ }^{17}$ The mass median diameter, relative span (90\% undersize to $10 \%$ undersize $/ 50 \%$ undersize), and percentage of particles smaller than $5 \mu \mathrm{m}$ $(\% \leq 5 \mu \mathrm{m})$ were determined. The respirable fraction was determined as the percentage of the emitted dose with particles $\leq 5 \mu \mathrm{m}$ reported relative to the measured nominal dose.

\section{Statistical Data}

Data are expressed as means $\pm \mathrm{SD}$. The KolmogorovSmirnov test confirmed the normal distribution of data. A statistical analysis was carried out by using unpaired $t$ tests for comparison between devices (Instat, GraphPad Software, San Diego, California). A $P$ value $<0.05$ was defined as statistically significant.

\section{Results}

\section{Duration, Aerosol Output, Albuterol Deposition, and} Temperature

The ultrasonic nebulizer was the fastest device, with a nebulization duration of 6 min (Table 1). The jet nebulizer was the slowest; its nebulization process stopped after $15 \mathrm{~min}$, before the reservoir was empty. In terms of the dose of albuterol emitted during nebulization, vibrating mesh nebulizers were the most effective devices, delivering $2 \mathrm{mg}$ of albuterol. The vibrating mesh nebulizers were 1.4 and 2.3 times more effective than the ultrasonic nebulizer and jet nebulizer, respectively. No difference between the 2 vibrating mesh nebulizer devices was observed.

Table 2 reports the amounts of albuterol sulfate retained in different parts of the system. The simulated pulmonary delivery of albuterol (ie, amount of albuterol on the filters) varied markedly according to nebulizer type, from $28.4 \pm 4.9 \%$ for the jet nebulizer to $76.6 \pm 5.0 \%$ for the 
Physicochemical Aspects and Efficiency of Nebulization

Table 2. Nebulized Albuterol Deposition in the In Vitro Model

\begin{tabular}{|c|c|c|c|c|}
\hline Nebulizers & Filter Retention $(\%)^{* \dagger}$ & Nebulizer Retention $(\%)^{*}$ & Connector Retention (\%)* & Total Retention $(\%)^{*}$ \\
\hline Jet $(\mathrm{SN})$ & $28.4 \pm 4.9$ & $59.2 \pm 4.1$ & $6.9 \pm 1.7$ & $94.5 \pm 2.9$ \\
\hline Ultrasonic (MN) & $48.4 \pm 6.0$ & $32.7 \pm 5.2$ & $13.4 \pm 2.3$ & $94.5 \pm 3.3$ \\
\hline Vibrating mesh (AP) & $75.1 \pm 10.3$ & $3.7 \pm 1.2$ & $14.2 \pm 4.6$ & $93.0 \pm 5.7$ \\
\hline Vibrating mesh (AS) & $76.6 \pm 5.0$ & $2.2 \pm 0.5$ & $12.0 \pm 4.6$ & $90.8 \pm 4.1$ \\
\hline \multirow[t]{3}{*}{$P<.001$} & SN vs MN & SN vs MN & $\mathrm{SN}$ vs AP & NS \\
\hline & SN vs AP/AS & SN vs AP/AS & SN vs MN & \\
\hline & MN vs AP/AS & MN vs AP/AS & & \\
\hline \multirow[t]{3}{*}{$P>.05(\mathrm{NS})$} & AP vs AS & AP vs AS & SN vs AS & \\
\hline & & & MN vs AP/AS & \\
\hline & & & AP vs AS & \\
\hline \multirow[t]{4}{*}{$P>.04(\mathrm{NS})$} & & & & $\mathrm{SN}$ vs AP/AS \\
\hline & & & & MN vs AP/AS \\
\hline & & & & AP/AS \\
\hline & & & & $\mathrm{SN} / \mathrm{MN}$ \\
\hline \multicolumn{5}{|c|}{ * Mean \pm SD $(n=5)$, expressed as $\%$ of the initial dose of albuterol sulfate. } \\
\hline \multicolumn{5}{|c|}{$\dagger$ Nebulized albuterol delivery. } \\
\hline \multicolumn{5}{|c|}{ NS = statistically not significant } \\
\hline \multicolumn{5}{|c|}{ SN $=$ Sidestream nebulizer } \\
\hline \multicolumn{5}{|l|}{ MN = Multisonic nebulizer } \\
\hline \multicolumn{5}{|l|}{$\mathrm{AP}=$ Aerogen Pro nebulizer } \\
\hline AS $=$ Aerogen Solo nebulize & & & & \\
\hline
\end{tabular}
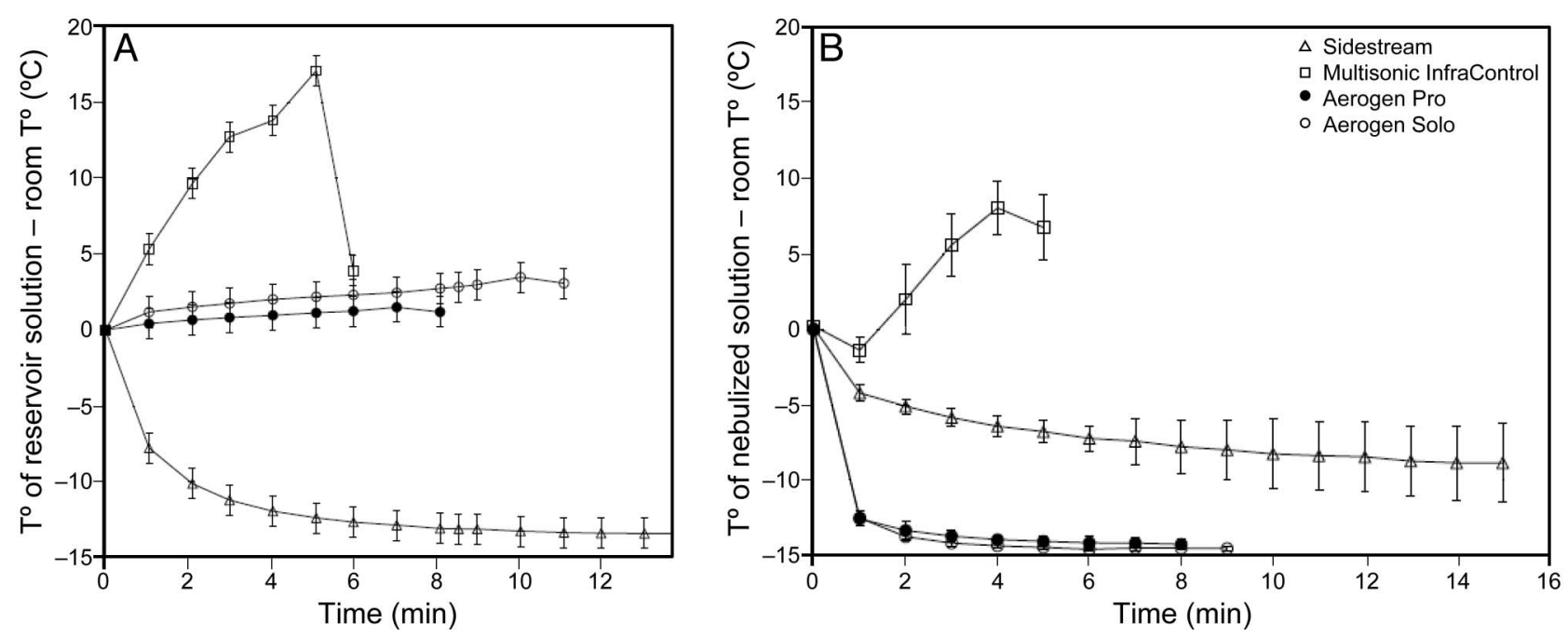

Fig. 3. Evolution of $A$ : reservoir solution and $B$ : nebulized solution temperature during nebulization $(0=$ room temperature).

Aerogen Solo. Albuterol deposition on filters was 2.7- and 1.6-fold greater for vibrating mesh nebulizers than for the jet nebulizer and ultrasonic nebulizer, respectively. A good correlation was observed between the emitted dose of albuterol and its retention on filters $\left(\mathrm{r}^{2}=0.95, P<.0001\right)$. The largest amount of albuterol remained in the reservoir in the jet nebulizer $(59.2 \pm 4.1 \%)$ and the smallest amount remained in the Aerogen Solo $(2.2 \pm 0.5 \%)$.

Temperature variations are presented in Figure 3. The temperature of the solution in the ultrasonic nebulizer reservoir increased progressively and substantially by
$20.4 \pm 4.8^{\circ} \mathrm{C}$ above a room temperature of $23.6 \pm 0.04^{\circ} \mathrm{C}$. A more modest increase of $8.4 \pm 1.0^{\circ} \mathrm{C}$ was observed for the nebulized solution (aerosol in the T-piece). In contrast, the temperature of the reservoir and nebulized solutions in the jet nebulizer decreased gradually, by $13.5 \pm 0.8^{\circ} \mathrm{C}$ and $8.8 \pm 2.6^{\circ} \mathrm{C}$, respectively, below room temperature. With the vibrating mesh nebulizers, the temperature of the reservoir solution remained slightly above room temperature $\left(1.5 \pm 0.3^{\circ} \mathrm{C}\right.$ for the Aerogen Pro and $3.5 \pm 0.1^{\circ} \mathrm{C}$ for the Aerogen Solo), but the temperature of the nebulized solution (aerosol in the T-piece) decreased by $14.5 \pm 0.1{ }^{\circ} \mathrm{C}$. 
For the vibrating mesh nebulizers, similar tests carried out without gas flow showed the same trend, namely, a decrease of $6.3 \pm 3.1^{\circ} \mathrm{C}$.

\section{Osmolality and Concentration of Albuterol in the Reservoir Solution}

The osmolality (Fig. 4) was 1.5- and 1.3-fold higher $(453 \pm 30 \mathrm{mOsm} / \mathrm{kg}$ and $379 \pm 34 \mathrm{mOsm} / \mathrm{kg})$ with the jet nebulizer and ultrasonic nebulizer, respectively, at the end of nebulization, whereas it was stable with the vibrating mesh nebulizers $(295 \pm 3 \mathrm{mOsm} / \mathrm{kg}$ and $290 \pm 4 \mathrm{mOsm} / \mathrm{kg}$ ). Changes in albuterol concentrations in the reservoir during nebulization are shown in Figure 5.

\section{Particle Size Distribution and Respirable Fraction}

The mass median diameter, relative span, percentage of particles smaller than $5 \mu \mathrm{m}$, and respirable fractions are shown in Table 3. The particle size was larger with the ultrasonic nebulizer than with the other nebulizers, but the difference was statistically significant only compared with the Aerogen Solo $(P<.01)$. Based on these results, the respirable fraction of albuterol was clearly greater with the vibrating mesh nebulizers than with the jet nebulizer and ultrasonic nebulizer. The 2 vibrating mesh nebulizer types also afforded statistically different respirable fractions.

\section{Discussion}

The aim of this study was to investigate whether new devices such as an ultrasonic nebulizer and vibrating mesh nebulizers delivered more aerosol than a jet nebulizer in our pediatric model.

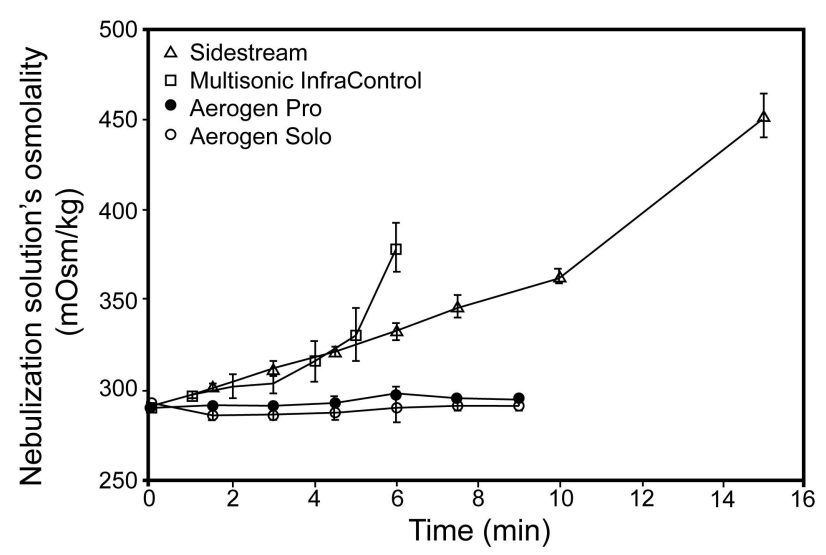

Fig. 4. Variation of osmolality of the nebulization solution during nebulization.

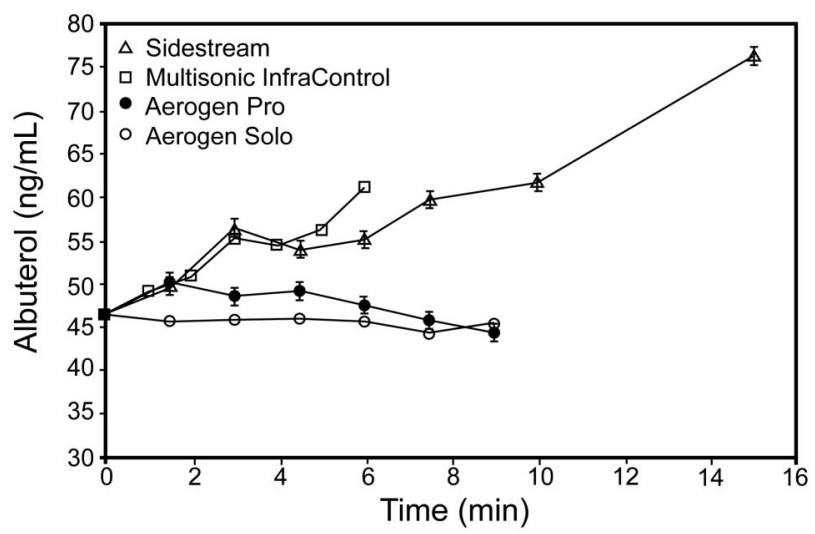

Fig. 5. Evolution of albuterol sulfate concentration during nebulization.

\section{Duration, Aerosol Output, Albuterol Deposition, and Temperature}

Our results on the duration of nebulization compare well with the literature. ${ }^{11,18,19}$ They are particularly consistent with those of Winterhalter et al, ${ }^{18}$ who reported for the ultrasonic nebulizer a nebulization duration of $10.1 \pm 1.7 \mathrm{~min}$ with $5 \mathrm{~mL}$ of Tc-99m $0.9 \% \mathrm{NaCl}$. In other words, the congruence of our results with the literature would suggest that the ultrasonic nebulizer was the fastest among the nebulizer tested. The aerosol output ( $\mathrm{g} / \mathrm{min}$ ) measured in our study was consistent with the manufacturer's specifications, except for the jet nebulizer, for which the observed output was less than half that of the manufacturer's specifications, as confirmed by others. ${ }^{20}$ Sidestream is a device with an open vent incorporated on top of the reservoir. ${ }^{21}$ However, in our model imitating a ventilator circuit, the T-piece hinders the open vent and the jet nebulizer can be considered as a traditional one. ${ }^{12}$ Under normal conditions of use with the open vent, auxiliary air is drawn through the vent resulting in a greater aerosol output. The duration of nebulization and treatment should also be considered, given their impact on patient compliance. ${ }^{21,22}$ Indeed, shorter treatment durations are associated with increased patient compliance. Although this criterion is not very relevant for mechanical ventilation, it may be important in ambulatory care.

A significant difference in albuterol delivery was found between nebulizer types. New devices, such as the ultrasonic nebulizer and vibrating mesh nebulizers, delivered more aerosol compared with jet nebulizer. Using a comparable design, Fink et $\mathrm{al}^{23}$ showed that the inhaled mass generated by a vibrating mesh nebulizer was $1.3-4.5$ times higher than with jet nebulizers and 0.8-2.4 times higher than with ultrasonic nebulizers. The same authors showed in a subsequent study 24 that the amount of albuterol delivered and the fine-particle fraction were 1.3-15 times 
Physicochemical Aspects and Efficiency of Nebulization

Table 3. Particle Size Distribution

\begin{tabular}{|c|c|c|c|c|c|}
\hline Nebulizers & $\operatorname{MMD}^{*}(\mu \mathrm{m})$ & Relative Span*† & $\% \leq 5 \mu \mathrm{m}^{*}$ & $\begin{array}{l}\text { Respirable Fraction of } \\
\text { Aerosol } \$(\%)\end{array}$ & $\begin{array}{c}\text { Respirable Fraction of } \\
\text { Albuterol } \$(\%)\end{array}$ \\
\hline Jet (SN) & $5.00 \pm 0.36$ & $1.72 \pm 0.06$ & $50.2 \pm 4.0$ & $28.8 \pm 2.4$ & $21.3 \pm 2.0$ \\
\hline Ultrasonic (MN) & $5.80 \pm 0.07$ & $2.30 \pm 0.02$ & $42.3 \pm 0.6$ & $31.1 \pm 1.3$ & $28.8 \pm 2.1$ \\
\hline Vibrating mesh (AP) & $5.14 \pm 0.54$ & $1.63 \pm 0.12$ & $49.0 \pm 6.3$ & $47.1 \pm 0.5$ & $47.2 \pm 0.5$ \\
\hline Vibrating mesh (AS) & $4.60 \pm 0.54$ & $1.70 \pm 0.03$ & $55.6 \pm 8.3$ & $54.5 \pm 0.4$ & $54.4 \pm 0.3$ \\
\hline$P<.05$ & & & $\mathrm{MN}$ vs $\mathrm{AP}$ & & \\
\hline$P<.01$ & MN vs AS & & $\begin{array}{l}\text { MN vs AS } \\
\text { MN vs SN }\end{array}$ & & \\
\hline$P<.001$ & & $\mathrm{MN}$ vs AS/AP/SN & & & \\
\hline$P<.0005$ & & & & & $\mathrm{MN}$ vs $\mathrm{SN}$ \\
\hline$P<.0001$ & & & & AP vs AS & AP vs AS \\
\hline & & & & MN vs AP/AS & MN vs AP/AS \\
\hline & & & & SN vs AP/AS & $\mathrm{SN}$ vs $\mathrm{AP} / \mathrm{AS}$ \\
\hline $\begin{array}{l}* \text { Mean } \pm \text { SD }(n=5) \\
\dagger \text { Relative span is the distribu } \\
\text { † Respirable fraction is the en } \\
\text { MMD = mass median diamet } \\
\text { SN }=\text { Sidestream nebulizer } \\
\text { MN = Multisonic nebulizer } \\
\text { AP = Aerogen Pro nebulizer } \\
\text { AS = Aerogen Solo nebulizer }\end{array}$ & $\begin{array}{l}\text { dth based on the } 10 \% \\
\text { raction } \leq 5 \mu \mathrm{m} \text {. }\end{array}$ & and $90 \%$ quantiles $(90 \%$ to & dersize $/ 50 \%$ under & & \\
\hline
\end{tabular}

higher with a vibrating mesh nebulizer than with jet nebulizers. Harvey et $\mathrm{al}^{25}$ showed in vivo that total lung aerosol deposition was greater for ultrasonic nebulizers than for jet nebulizers, which we have confirmed.

An important difference between the nebulizers was seen in the amount of albuterol remaining after nebulization. Higher retention was seen for jet nebulizer $(59.2 \pm 4.1 \%$ after $15 \mathrm{~min}$ ) compared with the retention reported by $\mathrm{Di}$ Paolo et al $(32.4 \pm 1.6 \%$ after $30 \mathrm{~min}) .{ }^{11}$ A recent study from our group ${ }^{26}$ reported the same amount of albuterol left in the reservoir for ultrasonic nebulizers and vibrating mesh nebulizers after ventilation in a mechanically ventilated pediatric lung model. Nevertheless, our results are consistent when compared with measures of residual volume or mass declared by the manufacturer and described in the literature. ${ }^{18,24}$ As observed in Table 2, the distribution of albuterol after nebulization was strongly dependent on nebulizer type. The quantity of albuterol in the reservoir was significantly lower, whereas that on the filters was significantly higher for the vibrating mesh nebulizers, and there was no significant difference between the 2 types of vibrating mesh nebulizers (Aerogen Pro, which is the reusable model; and Aerogen Solo, which is the disposable model). Considering the quantity of aerosol generated, we can conclude that the vibrating mesh nebulizers are the most efficient nebulizers.

The various nebulizers show marked differences in the temperature profile of the nebulization solution. With the jet nebulizer, the drop in temperature can be explained by an evaporation of the solution created by the anhydrous propellant gas flow, as already observed in other stud- ies. ${ }^{13,22}$ In the clinic, the administration of cold air and hypo- or hypertonic solutions can induce paradoxical bronchospasms. ${ }^{27}$ With the ultrasonic nebulizer (ultrasonic frequency $1.7 \mathrm{MHz}$ ), a sudden temperature increase characterizes the end of nebulization, as most of the energy absorbed by the nebulizer solution is dissipated as heat. ${ }^{28}$ This situation leads to higher evaporation, as with jet nebulizers, ${ }^{29-31}$ which could be detrimental to thermolabile solutes such as proteins. ${ }^{28}$ A lower frequency $(128 \mathrm{kHz})$ created by the piezoelectric element in the vibrating mesh is associated with a smaller increase in electrical energy, as can be seen when comparing the vibrating mesh nebulizers and ultrasonic nebulizer. Fink et al, ${ }^{23}$ using the Aerogen Pro, described a similar trend. We also showed that the gas was not the source of temperature variation by measuring its temperature over a 15 -min period $\left(-0.1 \pm 0.13^{\circ} \mathrm{C}\right)$ (Fig. 3). With the vibrating mesh nebulizers, the temperature difference between the aerosol and the nebulization solution could be due to evaporation from the nebulizers' mesh.

\section{Osmolality and Concentration of Albuterol in the Reservoir Solution}

With the jet nebulizer and ultrasonic nebulizer, the osmolality of the reservoir solution increased, probably due to evaporation. What consequence this osmolality increase had on droplets cannot be guessed and was not measurable with our equipment. ${ }^{32,33}$ For the vibrating mesh nebulizers, the osmolality of the reservoir solution was stable, meaning that we could not observe any evaporation. However, 


\section{Physicochemical Aspects and EfFiciency of Nebulization}

the temperature of the nebulized solution dropped drastically during nebulization, indicating an evaporation that might render the aerosols hypertonic. In the nebulization phase, the evolution of the albuterol concentration in the reservoir solution was correlated with the evolution of osmolality, and we showed that each solute was nebulized in the same way.

\section{Particle Size Distribution and Respirable Fraction}

When a treatment targets the lungs, the inhaled aerosol should consist of particles of a given size range. Indeed, the spatial distribution of deposited particles and, consequently drug efficiency, are strongly affected by particle size. Larger particles $(>6 \mu \mathrm{m})$ tend mainly to deposit in the upper airways, limiting the amount of drugs delivered to the lung. Smaller particles $(<2 \mu \mathrm{m})$ deposit mainly in the alveolar region and are probably the most apt to act systemically, whereas particles of intermediate size (2$6 \mu \mathrm{m})$ are best suited to treat the central and small airways. ${ }^{34}$ Hence, even if the ultrasonic nebulizer gave the largest particle size, all 3 types of nebulizers proved satisfactory according to this criterion. Sangwan et al ${ }^{35}$ compared 2 jet nebulizers and found respirable fractions of $6 \%$ and $14 \%$. Skaria et al ${ }^{36}$ compared the respirable fraction of a vibrating mesh nebulizer (Omron NE U22) with the Sidestream. Their results were 2-fold lower than ours, but their nebulization time was $7 \mathrm{~min}$. We found a statistically significant difference between vibrating mesh nebulizers and other nebulizer types, between the Aerogen Pro vibrating mesh nebulizer and Aerogen Solo vibrating mesh nebulizer, and between the jet nebulizer and ultrasonic nebulizer. The ultrasonic nebulizer and jet nebulizer generated almost half as much respirable aerosol than vibrating mesh nebulizers. The vibrating mesh Aerogen Solo was 1.2 times more efficient than the vibrating mesh Aerogen Pro. The occurrence of such a difference is consistent with the fact that the 2 devices are designed using the same technology but are built differently (Fig. 1).

\section{Limitations of the Study}

The study presented here using an in vitro model was effective for comparing nebulizer types, but it has limitations. First, we compared only 3 types of nebulizers, and the model does not take the different modes of mechanical ventilation into account. Second, the in vitro model does not fully mimic clinical use and a single drug was tested. In a constant flow model, the drug was almost entirely captured by filters mimicking the lungs. However, in a breathing simulator model and in a clinical situation, part of the inhaled aerosol is expired by patients without any deposition. ${ }^{4,12}$ The amount of inhaled aerosol also may be reduced due to patients' health, ${ }^{4}$ for instance, airway ob- struction. ${ }^{5}$ Finally, the additional air flow pushed all the nebulized solution toward the filters and increased the filter deposition values.

\section{Conclusions}

Our in vitro model revealed important differences between nebulizer types, emphasizing in particular that the new vibrating mesh nebulizer devices deliver more aerosols than traditional jet nebulizers or ultrasonic nebulizers. Before the routine use of these nebulizers can be recommended, however, the differences in efficiency and physical features observed in vitro will have to be validated in a mechanically ventilated pediatric lung model and in clinical trials, and possible dosage adaptations will have to be determined to avoid overdosing.

\section{ACKNOWLEDGMENTS}

We thank Quentin de Halleux PT for technical assistance and Bernard Testa $\mathrm{PhD}$ for his critical reading of the article.

\section{REFERENCES}

1. O'Doherty MJ, Thomas SHL. Nebuliser therapy in the intensive care unit. Thorax 1997;52(Suppl 2):S56-S59.

2. Dolovich MB, Ahrens RC, Hess DR, Anderson P, Dhand R, Rau JL, et al. Device selection and outcomes of aerosol therapy: evidencebased guidelines. Chest 2005;127(1):335-371.

3. Guerin C, Fassier T, Bayle F, Lemasson S, Richard JC. Inhaled bronchodilator administration during mechanical ventilation: how to optimize it, and for which clinical benefit? J Aerosol Med 2008; 21(1):85-95.

4. Dhand R. Aerosol delivery during mechanical ventilation: from basic techniques to new devices. J Aerosol Med 2008;21(1):45-60.

5. Fok TF, Monkman S, Dolovich M, Gray S, Coates G, Paes B, et al. Efficiency of aerosol medication delivery from a metered-dose inhaler versus jet nebulizer in infants with bronchopulmonary dysplasia. Pediatr Pulmonol 1996;21(5):301-309.

6. Thomas SH, O'Doherty MJ, Page CJ, Treacher DF, Nunan TO. Delivery of ultrasonic nebulized aerosols to a lung model during mechanical ventilation. Am Rev Respir Dis 1993;148(4):872-877.

7. Torres A, Anders M, Anderson P, Heulitt MJ. Efficacy of metereddose inhaler administration of albuterol in intubated infants. Chest 1997;112(2):484-490.

8. Coleman DM, Kelly HW, McWilliams BC. Determinants of aerosolized albuterol delivery to mechanically ventilated infants. Chest 1996;109(6):1607-1613.

9. Ari A, Areabi H, Fink JB. Evaluation of aerosol generator devices at 3 locations in humidified and non-humidified circuits during adult mechanical ventilation. Respir Care 2010;55(7):837-844.

10. Ari A, Atalay OT, Harwood R, Sheard MM, Aljamhan EA, Fink JB. Influence of nebulizer type, position, and bias flow on aerosol drug delivery in simulated pediatric and adult lung models during mechanical ventilation. Respir Care 2010;55(7):845-851.

11. Le J, Ashley ED, Neuhauser MM, Brown J, Gentry C, Klepser ME, et al; Society of Infectious Diseases Pharmacists Aerosolized Antimicrobials Task Force. Consensus summary of aerosolized antimicrobial agents: application of guideline criteria: insights from the Society of Infectious Diseases Pharmacists. Pharmacotherapy 2010; 30(6):562-584. 


\section{Physicochemical Aspects and EfFiciency of Nebulization}

12. Di Paolo ER, Pannatier A, Cotting J. In vitro evaluation of bronchodilator drug delivery by jet nebulization during pediatric mechanical ventilation. Pediatr Crit Care Med 2005;6(4):462-469.

13. Di Paolo ER, Cotting J, Pannatier A. Physicochemical aspects of nebulization: comparison of five models of jet nebulizers. Eur Hosp Pharm 2000;6(3):83-87.

14. Dhand R. Nebulizers that use a vibrating mesh or plate with multiple apertures to generate aerosol. Respir Care 2002;47(12): 1406-1416.

15. Ghazanfari T, Elhissi AM, Ding Z, Taylor KM. The influence of fluid physicochemical properties on vibrating-mesh nebulization. Int J Pharm 2007;339(1-2):103-111.

16. Di Paolo ER. Optimisation de la nébulisation de salbutamol chez l'enfant sous ventilation mécanique. $\mathrm{PhD}$ Thesis, Lausanne University 2000 .

17. Vecellio None L, Grimbert D, Becquemin MH, Boissinot E, Le Pape A, Lemarié E, Diot P. Validation of laser diffraction method as a substitute for cascade impaction in the European project for nebulizer standard. J Aerosol Med 2001;14(1):107-114.

18. Winterhalter M, Bund M, Khaladj N, et al. Aerosol delivery by an ultrasonic nebulizer during different mechanical ventilation settings in a lung model: a pilot study. Drug Des Devel Ther 2008; $2: 1-7$

19. Fink JB, Simmons R. The role of dose volume in delivering albuterol sulfate with a low residual volume nebulizer. Chest 2003;124(4 Meeting Abstracts): $94 \mathrm{~S}$.

20. Loffert DT, Ikle D, Nelson HS. A comparison of commercial jet nebulizers. Chest 1994;106(6):1788-1792.

21. O'Callaghan C, Barry PW. The science of nebulised drug delivery. Thorax 1997;52(Suppl 2):S31-S44.

22. McCallion ONM, Taylor KMG, Bridges PA, Thomas M, Taylor AJ. Jet nebulisers for pulmonary drug delivery. Int J Pharm 1996;130(1): $1-11$.

23. Fink JB, Simon M, MacLoughlan R, Behan N. In vitro comparison of a novel nebulizer with ultrasonic and pneumatic nebulizers. J Allergy Clin Immunol 2003;111(2) (Suppl 2):S143. DOI:10.1016/ S0091-6749(03)80454-2.
24. Fink JB. New technology offers new opportunities: continuous bronchodilator therapy during mechanical ventilation. Respir Ther 2007; 2(4):29-32.

25. Harvey CJ, O'Doherty MJ, Page CJ, Thomas SH, Nunan TO, Treacher DF. Comparison of jet and ultrasonic nebulizer pulmonary aerosol deposition during mechanical ventilation. Eur Respir J 1997;10(4): 905-909.

26. Sidler-Moix AL, Dolci U, Berger-Gryllaki M, Pannatier A, Cotting J, Di Paolo ER. Albuterol delivery in an in vitro pediatric ventilator lung model: comparison of jet, ultrasonic, and mesh nebulizers. Pediatr Crit Care Med 2013 Feb;14(2):e98-e102.

27. Cocchetto DM, Sykes RS, Spector S. Paradoxical bronchospasm after use of inhalation aerosols: a review of literature. J Asthma 1991;28(1):49-53.

28. Niven RW, Ip AY, Mittelman S, Prestrelski SJ, Arakawa T. Some factors associated with the ultrasonic nebulization of proteins. Pharm Res 1995;12(1):53-59.

29. Steckel H, Eskandar F. Factors affecting aerosol performance during nebulization with jet and ultrasonic nebulizers. Eur J Pharm Sci 2003;19(5):443-455.

30. Khatri L, Taylor KM, Craig DQ, Palin K. An assessment of jet and ultrasonic nebulisers for the delivery of lactate dehydrogenase solutions. Int J Pharm 2001;227(1-2):121-131.

31. Taylor KMG, Venthoye G, Chawla A. Pentamidine isethionate delivery from jet nebulisers. Int J Pharm 1992;85(1-3):203-208.

32. Phipps PR, Gonda I. Droplets produced by medical nebulizers: some factors affecting their size and solute concentration. Chest 1990; 97(6):1327-1332.

33. Phipps PR, Gonda I. Evaporation of aqueous aerosols produced by jet nebulizers: effects on particle size and concentration of solution in the droplets. J Aerosol Med 1994;7(3):239-258.

34. Darquenne C. Aerosol deposition in health and disease. J Aerosol Med Pulm Drug Deliv 2012;25(3):140-147.

35. Sangwan S, Condos R, Smaldone G. Lung deposition and respirable mass during wet nebulization. J Aerosol Med 2003;16(4):379-386.

36. Skaria S, Smaldone G. Omron NE U22: comparison between vibrating mesh and jet nebulizer. J Aerosol Med Pulm Drug Deliv 2010; 23(3): $173-180$. 